\title{
Under-expression of miR-100 may be a new Carcinogenic pathway for low-grade pTa Bladder Urothelial Carcinomas
}

Nelson Dip ${ }^{1 *}$, Sabrina T. Reis ${ }^{1}$, Luciana S. Timoszczuk', Daniel Kanda Abe ${ }^{1,2}$, Marcos Dall'Oglio², Miguel Srougi ${ }^{1}$ and Katia R. M. Leite ${ }^{1}$

${ }^{1}$ Laboratory of Medical Investigation, Urology Department - LIM55, University of Sao Paulo Medical School, Sao Paulo, Brazil

2Uro-Oncology Group, Urology Department, Sao Paulo Cancer Institute (ICESP), Sao Paulo, Brazil

\begin{abstract}
Objectives: The pathways involved in the carcinogenesis of bladder urothelial carcinoma have been well established and are used for the development of new diagnostic and prognostic markers for the disease. The main genetic pathway for the development of low-grade pTa urothelial carcinomas is related to FGFR3 mutation. MicroRNAs have been related to processes involved in carcinogenesis in many organs, and miR-100 was recently shown to target FGFR3 messenger RNA. Our aim was to study the profile of expression of miR-100 and FGFR3 in low-grade, pTa bladder urothelial carcinoma.
\end{abstract}

Methods and Materials: Using qRT-PCR, we studied the expression of miR-100 and FGFR3 in 30 patients who had undergone transurethral resection of low-grade, pTa bladder urothelial carcinoma.

Results and Conclusion: There was under-expression of miR-100 and over-expression of FGFR3 in 100\% of the specimens. Under-expression of miR-100 might be an alternative pathway for low-grade pTa urothelial bladder carcinogenesis and the identification of this molecular alteration may constitute a new diagnostic and prognostic marker for the disease.

Keywords: Micro RNA; Bladder cancer; Carcinogenesis; Molecular pathway; Prognosis; Diagnosis; FGFR3

\section{Introduction}

Bladder cancer $(\mathrm{BC})$ is the second most common malignancy of the urinary tract. Approximately 383,300 new cases are estimated for 2011 [1]. Ninety percent of BC are urothelial carcinomas (UC), previously named transitional cell carcinomas, and the majority are papillary lowgrade, non-muscle invasive that recur in up to $80 \%$ of cases but rarely progress to muscle invasion [2-3]. In contrast, 10 to $20 \%$ of tumors are muscle invasive at diagnosis, and $50 \%$ of patients die from metastatic disease [4].

The molecular pathways underlying the main two distinct types of UC, low-grade, non-muscle invasive, and high-grade, muscle invasive $[2,5]$ have been investigated to identify new potential markers for diagnosis, disease monitoring, prognosis and development of new targeted therapies [2,6,7]. The most common genetic alteration of $\mathrm{BC}$ associated with low-grade and stage neoplasias is an activating mutation of the fibroblast growth factor receptor 3 (FGFR3) gene [89], whereas mutations in the p53 and retinoblastoma (RB1) genes have as being identified as characteristic of the carcinogenesis pathway for high grade invasive disease $[5,7,10,11]$.

The FGFR3 gene belongs to the growth factor receptor family related to the tyrosine kinase signaling pathway, which plays an important role in embryogenesis, development, angiogenesis, wound healing, tissue homeostasis and tumorigenesis, regulating cellular proliferation, migration and apoptosis [9]. Mutations are the primary phenomenon related to FGFR3 dysfunction allowing its ligand-independent operation $[9,12]$ and the identification of FGFR3 dysfunction has been purposed as a new tumor marker $[5,10,13]$. Other events that may lead to the over-expression of the FGFR3 including alterations in the epigenetic control as DNA methylation, histone acetylation and abnormalities in the expression of microRNAs can also play crucial roles in the development and progression of BC [14].

MicroRNAs are members of small single-stranded regulatory RNAs (21-25 nucleotides) that can suppress the translation or promote the degradation of mRNA regulating the expression of target genes, including transcription factors, oncogenes and tumor suppressor genes. MicroRNAs have been reported to be differentially expressed in several types of cancers. Currently, there are more than 1400 miRNAs described in humans, and up to $30 \%$ of genes are thought to miRNA regulated [15]. MicroRNAs are involved in cell development, differentiation, apoptosis, tissue homeostasis and several metabolic pathways [16-19], and they have been related to carcinogenesis acting as negative regulators of genes related to cancer as typified by the effect of miR-15a and miR-16-1 on BCL2 mRNA, miR-143 and miR-let7c on RAS mRNA and miR-21 on p53 mRNA [20-23].

Recently authors have demonstrated that the FGFR3 gene is a target of micro RNA 100 (miR-100), and overactivation of FGFR3 could be involved in the development of low-grade, non-muscle invasive UC $[23,24]$. Our aim was to study the expression of miR-100 and the FGFR3 gene in low-grade, non-invasive UC to validate a new carcinogenesis pathway that may be involved in the development of the disease and that could potentially be used as a new biomarker.

\section{Materials and Methods}

\section{Patients}

Thirty low-grade non-invasive pTa urothelial carcinomas obtained

*Corresponding author: Nelson Gaspar Dip Júnior, Urology Department, Sao Paulo Cancer Institute, Sao Paulo, Brazil, Tel: +55-11-30617183; Fax: +55-11 30617183; E-mail: Nelson.dip@hotmail.com

Received November 17, 2011; Accepted December 07, 2011; Published December 13, 2011

Citation: Dip N, Reis ST, Timoszczuk LS, Abe DK, Dall'Oglio M, et al. (2012) Under-expression of miR-100 may be a new Carcinogenic pathway for low-grade pTa Bladder Urothelial Carcinomas. J Mol Biomark Diagn 3:121. doi:10.4172/21559929.1000121

Copyright: (c) 2012 Dip N, et al. This is an open-access article distributed under the terms of the Creative Commons Attribution License, which permits unrestricted use, distribution, and reproduction in any medium, provided the original author and source are credited 
Citation: Dip N, Reis ST, Timoszczuk LS, Abe DK, Dall'Oglio M, et al. (2012) Under-expression of miR-100 may be a new Carcinogenic pathway for low-grade pTa Bladder Urothelial Carcinomas. J Mol Biomark Diagn 3:121. doi:10.4172/2155-9929.1000121

Page 2 of 3

from patients who underwent transurethral resection were the subject of the study. Eighty-seven percent (26/30) of patients were male; the mean age was 67.6 years old, ranging from 47 to 82 . As control, we used normal bladder tissue from five patients who had undergone retropubic prostatectomy to treat benign prostatic hyperplasia. All patients provided informed consent and the study design was approved by the Institutional Board of Ethics protocol 10/176.

A subsection of the all the specimens were fixed in $10 \%$ formalin routinely processed and stained with hematoxylin and eosin for histological examination. Only urothelial low-grade (2004 WHO/ ISUP) pTa (2010 AJCC/TNM) tumors were included in the study.

\section{RNA and miRNA extraction and amplification}

Part of the resected tissue was immediately frozen and stored at $-80^{\circ} \mathrm{C}$. At the time of the RNA and microRNA extraction, a fragment of the frozen tissue was fixed in $10 \%$ formalin, routinely processed and embedded in paraffin and a slide was stained with hematoxylin and eosin to guarantee the presence of tumor in at least $75 \%$ of the specimen.

miR-100 expression was examined in all 30 cases; however, because of the relatively small amount of tissue available, FGFR3 messenger RNA expression was only examined in 15 cases.

Total RNA and miRNA were isolated using a RNAaqueous $\mathrm{Kit}^{\circledR}$ (Applied Biosystems, CA, USA) and a mirVana Kit ${ }^{\circledR}$ (Applied Biosystems, CA, USA), respectively, according to the manufacturer's instructions. RNA and miRNA concentration was determined by 260/280 nM absorbance using Nanodrop ${ }^{\circledR}$ ND-1000 spectrophotometer (Thermo Scientific). cDNA was generated using a High Capacity cDNA Reverse Transcription Kit ${ }^{\circledR}$ (Applied Biosystems, CA, USA) for RNA and a Taqman MicroRNA Reverse Transcription Kit ${ }^{\circledR}$ (Applied Biosystems, CA, USA) for miRNA. RNA reactions were incubated at $25^{\circ} \mathrm{C}$ for $10 \mathrm{~min}$, followed by $37^{\circ} \mathrm{C}$ for $120 \mathrm{~min}$ and $85^{\circ} \mathrm{C}$ for $5 \mathrm{~min}$, and the miRNA was incubated at $16^{\circ} \mathrm{C}$ for $30 \mathrm{~min}, 42^{\circ} \mathrm{C}$ for $30 \mathrm{~min}$ and $85^{\circ} \mathrm{C}$ for $5 \mathrm{~min}$. The $\mathrm{cDNA}$ was stored at $-20^{\circ} \mathrm{C}$ until further use.

For mRNA and miRNA amplification, a Taqman Reagent $\mathrm{Kit}^{\mathbb{B}}$ (Applied Biosystems, CA, USA) was used in the 7500 Fast Real-Time PCR System ${ }^{\circledR}$ (Applied Biosystems, CA, USA).

Expression profiles of miR-100 and FGFR3 mRNA were obtained by relative quantification determined using the $2^{-\Delta \Delta c t}$ method. Reactions were conducted in duplicate using $\beta-2$ microglobulin (B2M) as an endogenous control for mRNA analysis and RNU-43 and RNU-48 as endogenous controls for miRNA analysis.

\section{Statistic analysis}

The distribution of the expression levels of the miRNAs was skewed; therefore, the data were log transformed for analyses. Results are presented as geometric means with a $95 \%$ confidence interval $(95 \%$ $\mathrm{CI})$.

\section{Results and Discussion}

The data for miR-100 and FGFR3 expression are presented in Table 1 and Figure 1. All examined cases displayed under-expression of miR100 and over-expression of FGFR3. The mean and median expression values for miR-100 and FGFR3 were 0.038 and 0.0008 (8.94E-13 $0.44)$, and 1599.6 and 202.95 (3.26 - 16002.3), respectively.
Molecular pathways are directly involved in the biological behavior of $\mathrm{BC}$ and are able to predict disease evolution prior to its complete presentation. Our study revealed that $100 \%$ of low-grade pTa UC showed under-expression of miR-100 (30/30) and over-expression of FGFR3 (15/15), showing a strict association between two events. We

\begin{tabular}{|c|c|c|}
\hline Cases & miR-100 & FGFR3 \\
\hline 1 & 2.1E-08 & 697.34 \\
\hline 2 & 0.1982 & 274.56 \\
\hline 3 & 0.0831 & 240.35 \\
\hline 4 & 0.0008 & 5556.65 \\
\hline 5 & 0.0006 & 202.95 \\
\hline 6 & 0.0003 & 289.01 \\
\hline 7 & 0.0008 & 313.21 \\
\hline 8 & 0.0086 & 112.59 \\
\hline 9 & 3.4E-08 & 16002.39 \\
\hline 10 & 0.1172 & 3.26 \\
\hline 11 & 0.44 & 19.67 \\
\hline 12 & 0.0726 & 92.34 \\
\hline 13 & 0.0007 & 11.09 \\
\hline 14 & 0.0074 & 64.22 \\
\hline 15 & 0.0011 & 132.33 \\
\hline 16 & 8.9E-13 & - \\
\hline 17 & 1.21E-12 & - \\
\hline 18 & $3.14 \mathrm{E}-11$ & - \\
\hline 19 & 2.87E-09 & - \\
\hline 20 & 6.11E-10 & - \\
\hline 21 & 2.85E-08 & - \\
\hline 22 & 1.18E-07 & - \\
\hline 23 & 1.31E-08 & - \\
\hline 24 & 2.03E-08 & - \\
\hline 25 & 0.1099 & - \\
\hline 26 & 0.0014 & - \\
\hline 27 & 0.0030 & - \\
\hline 28 & 0.0732 & - \\
\hline 29 & 0.0237 & - \\
\hline 30 & 0.0009 & - \\
\hline
\end{tabular}

Table 1: miR-100 and FGFR3 expression values.

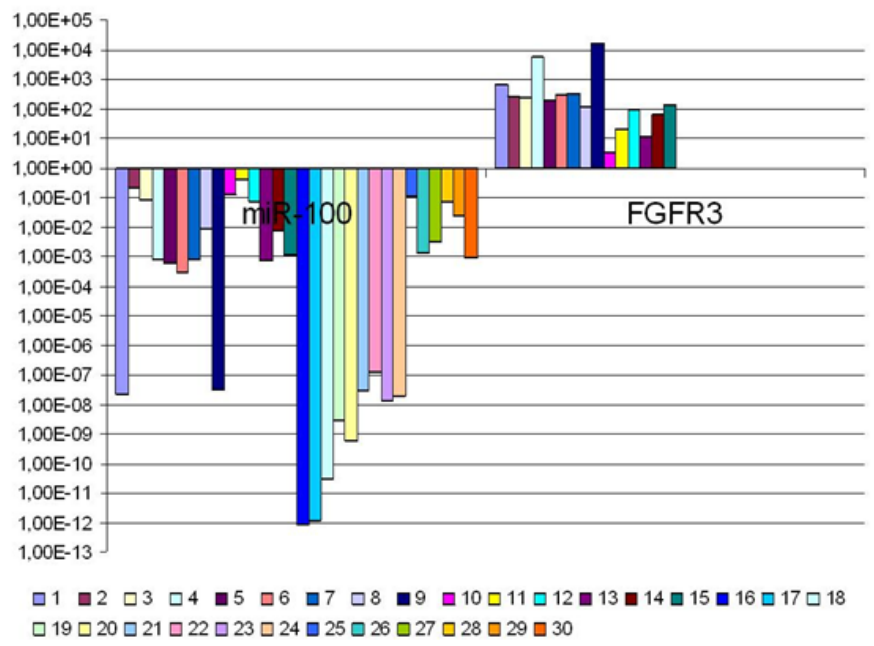

Figure 1: Expression levels of miR-100 and FGFR3. Note underexpression of all low-grade non-invasive pTa tumors and $100 \%$ of robust over-expression of FGFR3. 
Citation: Dip N, Reis ST, Timoszczuk LS, Abe DK, Dall'Oglio M, et al. (2012) Under-expression of miR-100 may be a new Carcinogenic pathway for low-grade pTa Bladder Urothelial Carcinomas. J Mol Biomark Diagn 3:121. doi:10.4172/2155-9929.1000121

sought to prove that FGFR3 is a target of miR-100, and that FGFR3 over-expression is due to the under-expression of miR-100, which is a different mechanism related to $\mathrm{BC}$ carcinogenesis that could be used in clinical practice. Catto et al. (2009), who studied 22 cases of low-grade pTa UC, found the same result and proved FGFR3 as a target for miR100 in vitro models.

The FGFR3 mutation in BC was initially described in 1999 by Cappellen et al., who identified mutations in $35 \%$ of the tumors they examined. FGFR3 can be abnormally activated through two mechanisms. The first mechanism is the translocation $\mathrm{t}(4 ; 14)(\mathrm{p} 16.3$; q32) that results in an increase in mRNA, as has been described in multiple myeloma [26]. The second mechanism is an anomalous overactivation of the receptor by a point mutation [27]. Currently, the FGFR3 point mutation is well established in BC carcinogenesis; it is present in more than $70 \%$ of low-grade non-invasive UC $[5,9,13,23]$, and can be caused by tobacco smoke and contact with aromatic amines $[28,29]$. These mutations activate the tyrosine kinase domain, lowering the specificity for the ligand, promoting dimerization independent of the ligand or inducing autophosphorylation of the intracellular domain.

In contrast, approximately $30 \%$ of low-grade pTa UC do not have the FGFR3 mutation suggesting that other regulatory pathways may be involved in the pathogenesis of the tumor. Few studies have evaluated alternative mechanisms of FGFR3 dysfunction in BC $[13,23]$.

It is important to clarify the mechanisms that may be involved in the dysfunction of miR-100 expression. Blick et al. (2011) recently demonstrated that hypoxia could up-regulate FGFR3 and concomitantly down-regulate miR-100 in an HIF-1a dependent manner in BC. In addition, epigenetic events such as methylation could be involved in the silencing of miR-100 [31].

We hypothesize that mechanisms affecting miR-100 expression could be the first molecular event in low-grade pTa UC development, and there is a need for further studies to confirm the precise role of miR-100 as a controller of FGFR3 in BC. If these events precede FGFR3 mutation, we propose the search for miR-100 under-expression as a new tumor diagnostic and prognostic marker.

We have demonstrated a profile of miR-100 and FGFR3 expression in low-grade pTa UC that could precede or be an alternative pathway for bladder carcinogenesis. Further confirmation of the findings presented in this study would constitute new data for the development of novel diagnostic and prognostic markers for bladder carcinogenesis.

\section{References}

1. Jemal A, Bray F, Center MM, Ferlay Ward E, Forman D (2011) Global Cancer Statistics, 2011. Cancer J Clin 61: 69-90.

2. Jebar AH, Hurst CD, Tomlinson DC, Johnston C, Taylor CF, et al. (2005) FGFR3 and Ras gene mutations are mutually exclusive genetic events in urothelial cell carcinoma. Oncogene 24: 5218-5225.

3. McConkey DJ, Lee S, Choi W, Tran M, Majewski T, et al. (2010) Molecular genetics of bladder cancer: Emerging mechanisms of tumor initiation and progression. Urol Oncol 28: 429-440.

4. Borden LS, Clark PE, Hall MC (2005) Bladder Cancer. Curr Opin Oncol 17 275-280

5. van Rhijn BWG, van der Kwast TH, Vis AN, Kirkels WJ, Boevé ER, et al (2004) FGFR3 and P53 Characterize Alternative Genetic Pathways in the Pathogenesis of Urothelial Cell Carcinoma. Cancer Research 64: 1911-1914.

6. Martinez Torrecuadrada J, Cifuentes G, López Serra P, Saenz P, Martinez A et al. (2005) Targeting the Extracellular Domain of Fibroblast Growth Factor Receptor 3 with Human Single-Chain Fv Antibodies Inhibits Bladder Carcinoma Cell Line Proliferation. Clin Cancer Res 11: 6280-6290.
7. Castillo Martin M, Domingo Domenech J, Karni Schmidt O, Matos T, Cordon Cardo C (2010) Molecular pathways of urothelial development and bladder tumorigenesis. Urol Oncol 28: 401-408.

8. Knowles MA (2008) Molecular pathogenesis of bladder cancer. Int J Clin Onco 13: $287-297$

9. Pandith AA, Shah ZA, Siddiqi MA (2010) Oncogenic role of fibroblastic growth factor receptor 3 in tumorigenesis of urinary bladder cancer. Urol Oncol (in press).

10. Bakkar AA, Wallerand H, Radvanyi F, Lahaye JB, Pissard S, et al. (2003) FGFR3 and TP53 Gene Mutations Define Two Distinct Pathways in Urothelial Cell Carcinoma of Bladder. Cancer Res 63: 8108-8112.

11. Wu XR (2009) Biology of urothelial tumorigenesis: insights from genetically engineered mice. Cancer Metastasis Rev 28: 281-290.

12. Ornitz DM, Xu J, Colvin JS, McEwen DG, MacArthur CA, et al. (1996) Recepto Specificity of the Fibroblast Growth Factor Family. J Biol Chem 271: 15292 15297.

13. Tomlinson DC, Baldo O, Harnden P, Knowles MA (2007) FGFR3 protein expression and its relationship to mutation status and prognostic variables in bladder cancer. J Pathol 213: 91-98.

14. Carradori S, Cristini C, Secci D, Gulia C, Gentile V, et al. (2011) Current and emerging strategies in bladder câncer. Anticancer Agents Med Chem, Oct 25.

15. Lewis BP, Burge CB, Bartel DP (2005) Conserved Seed Pairing, Often Flanked by Adenosines, Indicates that Thousands of Human Genes are MicroRNA Targets. Cell 120: 15-20.

16. Ambros V (2003) MicroRNA Pathways in Flies and Worms. Cell 2003113 673-676.

17. Bartel DP (2004) MicroRNAs: Genomics, Biogenesis, Mechanism, and Function. Cell 116: 281-297.

18. Croce CM, Calin GA (2005) miRNAs, cancer and stem cell division. Cell 122 6-7

19. Blenkiron C, Miska E (2007) MiRNAs in cancer: approaches, aetiology diagnostics and therapy. Hum Mol Genet 16: 106-113.

20. Cimmino A, Calin GA, Fabbri M, lorio MV, Ferracin M, et al. (2005) miR-15 and miR-16 induce apoptosis by targeting BCL2. PNAS 102: 13944-13949.

21. Lin T, Dong W, Huang J, Pan Q, Fan X, et al. (2009) MicroRNA-143 as a Tumor Suppressor for Bladder Cancer. J Urol 181: 1372-1380.

22. Johnson SM, Grosshans H, Shingara J, Byrom M, Jarvis R, et al. (2005) RAS is Regulated by the let-7 MicroRNA Family. Cell 120: 635-647.

23. Catto JWF, Miah S, Owen HC, Bryant H, Myers K, et al. (2009) Distinct microRNA alterations characterize high and low grade bladder cancer. Cance Res 69: 8472-8481.

24. Nagaraja AK, Creighton CJ, Yu Z, Zhu H, Gunaratne PH, et al. (2010) A link between miR-100 and FRAP1/mTOR in clear cell ovarian cancer. Mol Endocrinol 24: 447-463.

25. Capellen D, Oliveira C, Ricol D, Medina SGD, de Medina S, Bourdin J, (1999) Frequent activating mutations of FGFR3 in human bladder and cervix carcinomas. Nat Genet 23: 18-20.

26. Richelda R, Ronchetti D, Baldini L, Cro L, Viggiano L, et al. (1997) A Nove Chromossomal Translocation $\mathrm{t}(4 ; 14)(\mathrm{p} 16.3 ; \mathrm{q} 32)$ in Multiple Myeloma Involves the Fibroblast Growth-Factor Receptor 3 Gene. Blood 90: 4062-4070.

27. Chesi M, Nardini E, Brents LA, Schröck E, Ried T, et al. (1997) Frequen translocation $\mathrm{t}(4 ; 14)(\mathrm{p} 16.3 ; \mathrm{q} 32.3)$ in multiple myeloma is associated with increased expression and activating mutations of fibroblastic growth facto receptor 3. Nat Genet 16: 260-264.

28. Markowitz SB, Levin K (2004) Continued Epidemic of Bladder Cancer in Workers Exposed to Ortho-Toluidine in a Chemical Factory. J Occup Environ Med 46: 154-160.

29. Kirkali Z, Chan T, Manoharan M, Algaba F, Busch C, et al. (2005) Bladde Cancer: Epidemiology, Staging and Grading, and Diagnosis. Urology 66: 4-34.

30. Blick C, McCormick R, Ramachandran A, Buffa F, Catto J, Harris AL (2011) The hypoxic and microRNA 100 regulation of FGFR3 in non-muscle invasive bladder cancer. (in press).

31. Choudhry H, Catto JWF (2011) Epigenetic Regulation of MicroRNA Expression in Cancer. Methods Mol Biol 676: 165-184. 